\section{Free Aryl Radicals in the Fittig and Ullmann Reactions}

Hey and Waters ${ }^{I}$ have given a valuable review of some organic reactions involving the formation of free radicals in solution. From this and from later work two properties stand out among others as being characteristic of free aryl radicals in solution. One of these is the persistence with which such radicals remove hydrogen from all solvents containing nonaromatic hydrogen, and so become converted to the corresponding aryl hydrogen compounds; and the other is the displacement by them of hydrogen from aromatic liquids to yield biaryls, the substitution occurring invariably ortho and para to substituents in the benzene ring, irrespective of their nature.

In a series of Ullmann, Fittig and related reactions carried out recently in this laboratory, it was consistently observed that one of the products formed on treating $\operatorname{ArX}(\mathrm{X}=\mathrm{Cl}, \mathrm{Br}$, or I) with sodium or copper was the corresponding aryl hydrogen compound ArH. It seemed probable that this was a result of the formation of free aryl radicals in the reaction, and that $\mathrm{ArH}$ was formed from these either by reaction with the diluent (ether), where this was present, or by dismutation when diluent was absent ${ }^{2}$.

In order to obtain confirmation of this view, iodobenzene was caused to react with copper bronze in a sealed tube in the presence of an excess of ethyl benzoate, when it was expected that free phenyl radicals if formed would displace hydrogen from the ortho and para positions in the ethyl benzoate. The product of the reaction was boiled with caustic alkali, and neutral material was separated by ether extraction. On acidification of the alkaline solution a mixture of acids was obtained, in which diphenyl2-carboxylic acid and diphenyl-4-carboxylic acid have been shown to be present. The latter was easily separated in a pure condition by fractional recrystallization, and the former, which was more difficult to purify, was shown to be present since fluorenone could be isolated from the reaction mixture after treatment with sulphuric acid. No evidence was obtained for the presence of any other components in the mixture.

The isolation of these substances is strong evidence for the formation of free radicals as intermediates in this reaction, and it and allied reactions are under investigation from a similar point of view. The results will be recorded elsewhere.

W. S. RaPson.

R. G. SHUTTLEworth.

Department of Chemistry,

University of Cape Town.

Feb. 1 .

${ }^{2}$ Hey and Waters, Chem. Rev., 21, 169 (1937).

${ }^{2}$ Cf. Hammett, "Physical Organic Chemistry", McGraw-Hill (1940), p. 144.

\section{Respiration of Leguminous Root Nodules.}

A PREvious communication from one of us (G. B. ${ }^{1}$ ) referred to observations on the rate of evolution of respiratory carkon dioxide from leguminous root nodules still attached to the plant. Those observations have been extended and are being published elsewhere. A brief report is presented here of other observations (which will not be continued at present) on detached nodules, made by means of a respirometer designed by one of us (G. F. A.). This apparatus provides concurrent records of oxygen intake and carbon dioxide evolution and is being described in another publication. It is our belief that the only complete figures for the respiratory gaseous exchange of nodules so far published are those of Allison and his collaborators ${ }^{2,3}$, though recently Wilson ${ }^{4}$ has recorded observations on oxygen intake. Information concerning respiratory events within the nodule will contribute to an increased understanding of the general metabolism of the nodule, including the process of nitrogen fixation.

The observations were made at a temperature of $25^{\circ} \mathrm{C}$. on nodules taken mostly from Manchu soya bean plants growing in solution culture. During the determinations the nodules usually were kept moistened with the inorganic nutrient solution in which the plants had been grown. All figures quoted refer to c. mm. oxygen absorbed or carbon dioxide evolved per hour per mgm. dry weight of tissue. In twelve experiments with nodules of various sizes from soya bean plants inoculated with Wisconsin strain No. 505 of the nodule organism, values ranging from $2 \cdot 31$ to $6 \cdot 25$ were obtained for oxygen intake. Using nodules from field-grown soya bean plants, Allison et al. ${ }^{2}$, at $28^{\circ} \mathrm{C}$., obtained lower values for oxygen intake in air (range $0 \cdot 76-2 \cdot 05$ ), while Wilson 4 reports a value of 1.53 for nodules from plants infected with strain 505. Allison et al. observed that the respiratory quotient was well above unity for nodules respiring in air, the range for soya bean nodules being $1 \cdot 23-2 \cdot 00$. Partly because of this type of result they concluded that partially anærobic conditions prevail within nodule tissues. In our material also the respiratory quotient was usually greater than unity (range I-1-25). For detached younger parts of the roots of the same soya bean plants, values of $1 \cdot 70-2 \cdot 17$ were obtained for oxygen absorption, with quotients very close to unity. The rate of respiration of the roots was thus inferior to that of the nodules, whereas Allison et al. ${ }^{3}$ concluded that in their material root and nodule respiration were of the same order. Wilson", on the other hand, observed root respiration to be considerably in excess of nodule respiration. It thus appears that the intensity of respiration within leguminous nodules and roots is liable to vary in material from different sources.

Contrary to the experience of Allison et al. ${ }^{2}$, in our material of soya bean nodules no definite tendency was detected for the respiratory quotient to be higher in larger nodules than in smaller ones, though observations on this point were not extensive. Nodules from plants infected with an ineffective strain of the nodule organism (No. 507) showed much lower rates of respiration (oxygen absorption $0 \cdot 7)$, though the respiratory quotient was similar to that characterizing nodules in which normal fixation was proceeding. For pea (Pisum sativum) nodules figures of $1 \cdot 89-3 \cdot 24$ were obtained for oxygen intake, the respiratory quotients ranging from $1 \cdot 05$ to $1 \cdot 25$. In all these observations the respiration measured is, of course, due partly to the plant tissues of the nodule as well as to the bacteria.
Botany Department,
University of Glasgow.
G. F. Asprey. April 29.

${ }^{1}$ Bond, Nature, 144, 906 (1939).

2 Allison, Ludwig, Hoover and Minor, Bot. Gaz., 101, 513 (1940).

${ }^{3}$ Allison, Ludwig, Minor and Hoover, Bot. Gaz., 101, 534 (1940).

"Wilson, "Biochemistry of Symbiotic Nitrogen Fixation" (1940). 